\title{
Proceeding
}

8th INSHS International Christmas Sport Scientific Conference, 5-7 December 2013. International Network of Sport and Health

Science. Szombathely, Hungary

\section{Topographic conditions and physical activity behaviour of young adults in Austria}

\author{
BARBARA SZABO , ERWIN GOLLNER, FLORIAN SCHNABEL \\ ${ }^{1}$ University of Applied Sciences Burgenland, Austria
}

\begin{abstract}
Szabo, B., Gollner, E. \& Schnabel, F. (2014). Topographic conditions and physical activity behaviour of young adults in Austria. J. Hum. Sport Exerc., 9(Proc1), pp.S210-S222. In Austria there is an east-west divide concerning the amount of physical activity that has been detected. This is associated with poorer health in the eastern region of Austria compared to the western. Experts think that differences in topographic conditions might be a reason for these differences. However this hypothesis until now has not been scientifically proven. This study incorporates a multi-staged approach. First, outdoor physical activity behaviour (levels of exercise, favourite activities etc.) among people aged between 18-35 and living in Burgenland $(n=150)$, as well as levels of physical activity in general, were compared with those of people at the same age living in Tyrol $(n=150)$, by using a semi-standardized quantitative online-survey. To determine if differences between these two groups were significant the chi-squared test was used. In addition satisfaction with opportunities for outdoor physical exercise, motives, barriers and wishes concerning design of green spaces were analysed. Finally experts, working in the field of physical activity promotion $(n=9)$, discussed within a focus group how to implement results into practice. The hypothesis that topographic conditions have an influence on physical activity behaviour was confirmed. For example, people living in Tyrol are more likely to engage in mountain sports than those living in Burgenland, while Nordic Walking is more popular in Burgenland compared to Tyrol $(P<0.05)$. The results also show that people living in Tyrol are more physically active in general $(P<0.05)$ as well as do more outdoor sport than people living in Burgenland $(P<0.05)$. In addition some barriers as well as need for action could be identified in both regions. The natural environment influences levels of physical activity as well as sport activities among local populations. However differences in topographic conditions are not like to be the only reason for east-west differences concerning levels and forms of physical activity. Expert recommendations need to be implemented in the future. Further research needs to be conducted to examine the role of other potential explanations for east-west differences. Key words: EAST-WEST GRADIENT, GREEN SPACE, OUTDOOR SPORT, GREEN EXERCISE
\end{abstract}

Corresponding author. University of Applied Sciences Burgenland, 7000 Eisenstadt, Campus 1, Austria.

E-mail: barbara.szabo@fh-pinkafeld.ac.at

8th INSHS International Christmas Sport Scientific Conference, 5-7 December 2013. International Network of Sport and Health Science. Szombathely, Hungary.

JOURNAL OF HUMAN SPORT \& EXERCISE ISSN 1988-5202

(c) Faculty of Education. University of Alicante

doi:10.14198/jhse.2014.9.Proc1.01

VOLUME 9 | Proc1 | 2014 | S210 


\section{INTRODUCTION}

Many studies have demonstrated that physical inactivity is an important societal problem in industrialized countries. For example, Klimont et al. (2007) found that only $60 \%$ of Austrian adult men and $49 \%$ of Austrian adult women are physically active enough to cause sweating at least once a week. These results stand in contrast to the Austrian Recommendations for Health-Enhancing Physical Activity (Titze et al., 2010), which state that adults should undertake one of the following:

- activity of moderate intensity (you can still talk during the activity, but singing would be impossible) for at least 150 minutes every week

- 75 minutes per week of vigorous activity (only a brief exchange of words is possible)

- an appropriate combination of moderate and vigorous physical activity

In addition, Klimont et al. (2007) identified an east-west divide concerning levels of physical activity in Austria. People living in the western regions of Austria (e.g. Tyrol) exercise more often than people living in the eastern regions (e.g. Burgenland). Specifically, the results show that $47.4 \%$ of adult people living in Burgenland and $54.7 \%$ of adult people living in Tyrol are physically active enough to cause sweating at least once a week, and $10.2 \%$ of Tyroleans say that they do competitive sports in general, compared to only $5.9 \%$ of Burgenlanders.

Many studies have scientifically proven the negative health consequences of a physically inactive lifestyle in today's society. This supports the Social Model of Health by Dahlgren and Whitehead (1991), which states that physical activity is an important influencing factor on public health. Due to these many studies, the World Health Organization (2010) identified physical inactivity as the fourth largest risk factor for global mortality and as an important reason for many diseases (e.g. breast cancer, colon cancer, diabetes, ischemic heart disease). Results of studies in Austria have confirmed the negative influence of physical inactivity on public health. Lower levels of physical activity among people living in the eastern regions of Austria are associated with poorer health compared to the western part of the country. For example, mortality due to cardiovascular diseases is $7 \%$ higher than the national average in Burgenland and $15 \%$ lower than the Austrian average in Tyrol (Urbas et al., 2008). In addition, $52.9 \%$ of people living in Burgenland are overweight or obese, compared to "only" $41 \%$ of people living in Tyrol (Klimont et al., 2007).

According to the Ottawa Charter (World Health Organization, 1986), health promotion is the process of enabling people to increase control over their health and improve it. One strategy for reaching this goal is creating supportive environments. Since physical activity has a significant influence on health, supportive environments also include spaces for doing sports. Studies in Austria (e.g. Weiß \& Russo, 2005) have shown that countryside and green spaces (e.g. meadows, forests, rivers, lakes) are the most attractive places for people to exercise. In addition, being in nature is one of the main motives for being physically active. Therefore, designing green spaces that are conducive to physical activity can be an important strategy for promoting physical activity in Austria.

Many authors (Fuchs, 2003; Titze et al., 2010; Brownson et al., 2001) have identified the natural environment as an important influencing factor on physical activity. According to De Vries (2010), nature in general promotes physical activity behaviour of the population in everyday life as well as sport behaviour in leisure time. More specifically, several authors (Kaczynski \& Henderson, 2008; Cohen et al., 2006; Coombes et al., 2010; Brownson et al., 2001; Cunningham \& Michael, 2004; Humpel et al., 2002) have 
found associations between physical activity behaviour of local populations and green spaces in the neighbourhood. In particular, the distance to green spaces from home (Toftager et al., 2011), the amount of green spaces (Ellaway et al., 2005), the kind of green spaces (Cohen et al., 2006) and the self-assessed aesthetics of green spaces (Hartig, 2008; Cunningham \& Michael, 2004) in neighbourhood seem to influence physical activity behaviour. However, some studies found no correlations between countryside and people's physical activity behaviour (Hillsdon et al., 2006; Witten et al., 2008). This shows that the existing literature concerning this topic has drawn no clear conclusions.

The Austrian provinces of Burgenland and Tyrol are characterised by different topographic conditions. While lowlands and hill lands dominate Burgenland, Tyrol has average to high mountains (Schwarz, 2002). Titze et al. (2010) posited that these differences in the natural environment are one reason for the eastwest divide concerning physical activity behaviour in Austria. The authors suggested that the mountains in the western regions are more inviting to exercise than the lowlands and hill lands in the eastern regions. However, before this study, this hypothesis had not been scientifically proven.

Based on scientific findings, the aim of the present study was to explore the potential link between the physical activity behaviour of people ages 18-35 living in Burgenland or Tyrol and topographic conditions. Other goals were to identify motives and barriers for being physically active in nature and expectations concerning the design of green spaces, as well as to develop recommendations for creating green spaces that are conducive to physical activity.

\section{MATERIALS AND METHODS}

Based on a systematic literature review, a multi-staged method concept was developed and deployed. The concept consists of a quantitative semi-standardized online survey and a focus group. This section describes the multi-staged method concept in detail.

Online survey

In a first step, the outdoor physical activity behaviour and levels of physical activity in general among people ages 18-35 living in Burgenland were compared with those of people at the same age living in Tyrol. Burgenland represents the eastern region of Austria, while Tyrol represents the western region.

Study population

The population of the quantitative online survey were Burgenlanders and Tyroleans between the ages of 18 and 35. According to Statistik Austria (2012), Tyrol contains about 170,000 inhabitants within that age group, and Burgenland contains 58,000. The inclusion criteria are age (18-35) and place of residence (Burgenland, Tyrol). The reasons for choosing the age group 18-35 were:

- Being in the nature is one of the main motives for young adults (18-35) to exercise (Weiß and Russo, 2005).

- Among young adults (18-35), a short distance to outdoor sport facilities is an important requirement for being physically active (Weiß \& Russo, 2005).

- Physical activity behaviour at a young age influences physical activity behaviour at an older age (Sprecher, 2010).

- Many Austrian people between the age of 18 and 35 are parents (Statistik Austria, 2012) and therefore have a role model function for their children. 
Using the method of disproportional sampling, the population was divided into subgroups (group 1: Burgenlanders between the age of 18 and 35; group 2: Tyroleans between the age of 18 and 35). This sampling method ensures that the representation of both groups in the sample is sufficient for drawing conclusions. A total of 150 respondents living in Burgenland and 150 respondents living in Tyrol responded to the survey. Therefore, the information obtained has to be valued with a statistical fluctuation rate of $+/-$ $8.1 \%$.

Group 1

Group 1 consisted of 55 male and 95 female Burgenlanders. Most respondents (72\%) were between the ages of 18 and 25 (26-29 years: 16\%; 30-35 years: 12\%). Most participants of group 1 had a high educational background (i.e. $48 \%$ had a higher school certificate, and $36 \%$ had a final degree).

\section{Group 2}

Group 2 consisted of 48 male and 102 female Tyroleans. Most respondents $(71 \%)$ were between the ages of 18 and 25 (26-29 years: 21\%; 30-35 years: 8\%). Most participants of group 2 had a high educational background (i.e. $55 \%$ had a higher school certificate and $38 \%$ had a final degree).

\section{Survey instrument}

Data was collected using a semi-standardized quantitative online survey. There was no previously existing valid questionnaire for measuring the outdoor physical activity behaviour of local populations. The questionnaire was based on existing valid instruments that measure physical activity behaviour (e.g. the Global Physical Activity Questionnaire). The survey was created using the online tool E-Questionnaire. It consisted of the following categories:

- physical activity behaviour in general

- outdoor physical activity behaviour

- satisfaction with outdoor opportunities for being physically active

- motives for being physically active in nature

- barriers for being physically active in nature

- desires concerning the design of green spaces

- sociodemographic data

\section{Data collection}

Before the field phase, the authors conducted a pre-test to analyse the comprehensibility, manageability and consistency of the developed questionnaire and to ensure its quality. After adapting the survey, data collection started. To access the target group, the virtual networks of 16 Austrian universities were used, as well as the social network Facebook. An onlinelink to the questionnaire was sent to the universities via email and posted on different Facebook sites. The data collection period lasted $1 \frac{1}{2}$ months.

\section{Statistical analyses}

Within the study, three hypotheses were generated:

$\mathrm{H} 1$ : Tyroleans between the ages of 18 and 35 are more physically active than Burgenlanders between the ages of 18 and 35.

H2: Topographic conditions influence the physical activity behaviour of people between the ages of 18 and 35 living in Burgenland or Tyrol.

H3: The motives of Tyroleans between the ages of 18 and 35 for being physically active in nature are different than those of Burgenlanders in the same age group. 
Frequency tables were constructed for all of the variables in the survey instrument. Stratification was performed by county, age, gender and educational background. To estimate the probability that the true population mean lies within a range around a sample mean, confidence intervals were calculated. To test the defined hypotheses and to calculate differences between group 1 and group 2, the chi-squared test was used. In all statistical tests, a probability level of $\mathrm{P}<0.05$ was deemed statistically significant. The statistical software package SPSS 18.0 was used for all statistical calculations.

\section{Focus group}

According to Mayerhofer (2009), focus groups are an appropriate method for identifying and analysing influencing factors and for generating hypotheses. Thus, a focus group was held, in which experts working in the field of physical activity promotion $(n=9)$ discussed the results of the quantitative survey. In particular, the topics discussed were:

- $\quad$ assessment of the results of the quantitative online survey

- importance of green spaces and countryside for physical activity behaviour

- outdoor sport facilities in Burgenland and Tyrol and their utilization

- recommendations for the design of green spaces that are conducive to physical activity, in order to improve the physical activity behaviour of Burgenlanders and Tyroleans between the ages of 18 and 35

- $\quad$ other explanations for the east-west divide concerning physical activity behaviour in Austria

The results of the quantitative online survey were presented first, after which the focus group participants discussed the topics listed above guided by a question list. The results were recorded in a protocol.

\section{RESULTS}

This section describes the main results of the quantitative online survey and the focus group.

Physical activity behaviour of Burgenlanders (group 1) and Tyroleans (group 2)

The hypothesis that Tyroleans between the ages of 18 and 35 exercise more often than Burgenlanders in the same age group was generally confirmed. A chi-squared analysis of levels of physical activity demonstrated a significant difference between groups 1 and $2(X 2=3.382, P<0.05)$. The greatest variation was found for the percentage of respondents who say that they exercise three or four times a week (group 1: $27 \%$, group 2: $38 \%$ ). Figure 1 provides detailed information.

How often do you exercise or do sports? Please choose the answer that best describes the frequency of your physical activity.

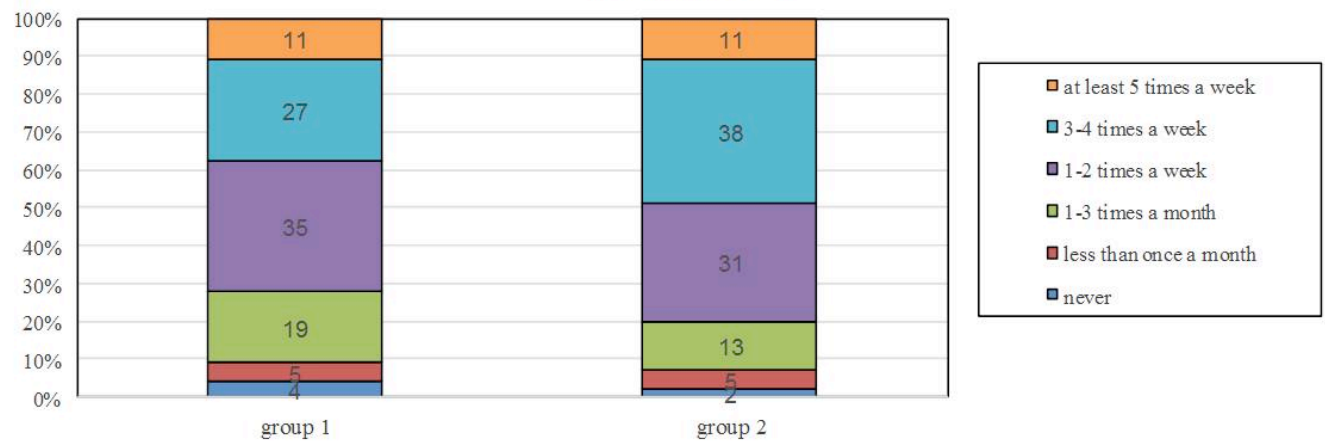

Figure 1. Levels of physical activity - group 1: $n=150$, group 2: $n=150 ; P<0.05$. 
These results are consistent with those of other Austrian studies concerning levels of physical activity in different provinces (e.g. Klimont et al., 2007).

On average, how long does one of your outdoor sport sessions last?

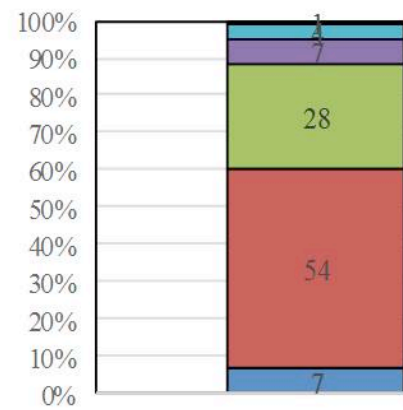

group 1

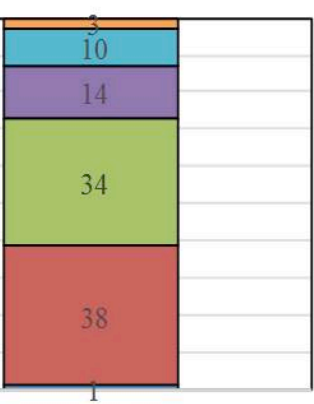

group 2

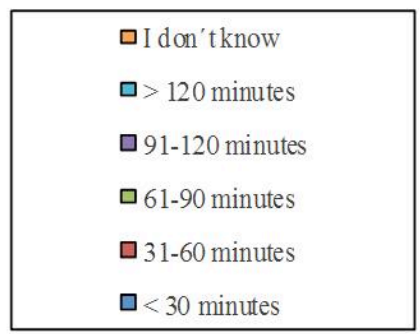

Figure 2. Average duration of an outdoor sport session: group 1: $n=138$; group 2: $n=145, P<0.05$.

How often do you exercise in nature?

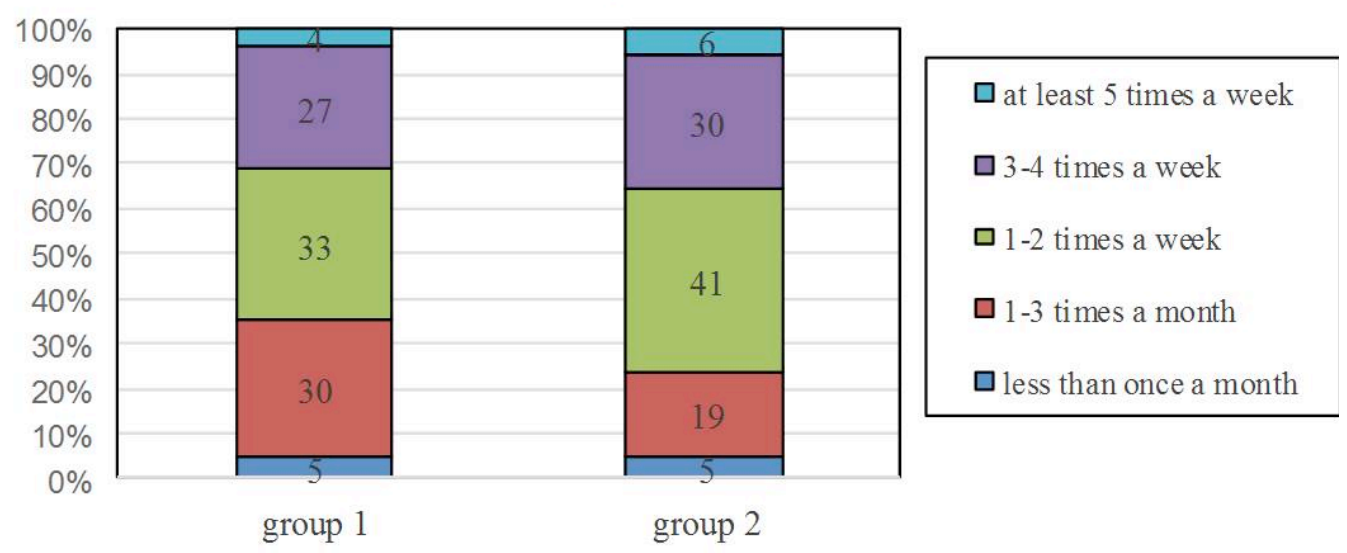

Figure 3. Amount of outdoor sport sessions: group 1: $n=138$; group 2: $n=145 ; P>0.05$

Participants from both provinces were also asked which sport activities they do in general. These results alone already indicated that nature plays a vital role for physical activity behaviour. The most popular sport activities in Burgenland are cycling/mountain biking (61\% "yes"), running/jogging (53\% "yes") and swimming (51\% "yes"), while in Tyrol skiing/snowboarding (67\% "yes"), hiking (65\% "yes"), running/jogging (54\% "yes") and cycling/mountain biking (52\% "yes") were the most popular.

A difference in general physical activity behaviour between the two groups was also evident in questions regarding organized sports. While only $44 \%$ of Burgenlanders said that they were members of a sport club, $51 \%$ of Tyroleans were in such a club. One possible explanation for this difference is the presence of hiking clubs in Tyrol. While only $6 \%$ of Burgenlanders were members of a hiking club, $22 \%$ of Tyroleans were.

Findings concerning outdoor physical activity behaviour show that in total $92 \%$ of respondents from Burgenland and $97 \%$ of respondents from Tyrol said that they do outdoor sports in general. The main 
difference was in the duration of exercise in nature, where Tyroleans had significantly longer times than Burgenlanders $(X 2=19.400, P<0.05)$. Figure 2 provides detailed information.

Concerning the amount of outdoor sport sessions, a chi-squared analysis detected no significant difference between Burgenlanders and Tyroleans $(X 2=5.751, P>0.05)$, although the results indicate that members of group 2 exercise more often in nature than those of group 1 (see figure 3 ).

In addition to differences concerning the amount of physical activity, the choice of outdoor sport activities also varied between the two groups. Chi-squared analyses show that there are significant differences between groups 1 and 2 concerning the outdoor sport activities listed in table 1. For activities which can only be practiced during specific seasons of the year only that period of time was considered when answering.

Summing these results up (see table 1), people living in mountainous Tyrol prefer mountain sports, while those living in the lowlands and hill lands of Burgenland more often engage in sport activities such as nordic walking and inline skating. Although there are differences between the two groups, there are also some similarities. In both provinces, the most common outdoor sport activities are running/jogging (group 1: $32 \%$ at least once a week $+/-4 \%$; group 2: $34 \%$ at least once a week $+/-4 \%$ ), cycling/biking (group 1: $27 \%$ at least once a week $+/-4 \%$; group 2: $30 \%$ at least once a week $+/-4 \%$ ) and walking (group 1: $25 \%$ at least once a week $+/-5 \%$; group 2: $26 \%$ at least once a week $+/-4 \%$ ).

Table 1. Frequency of doing specific outdoor sport activities: group 1: $n=138$; group 2: $n=145 ; P<0.05$.

\begin{tabular}{|c|c|c|c|c|c|c|c|c|c|c|c|}
\hline \multirow[t]{2}{*}{$\begin{array}{l}\text { outdoor sport } \\
\text { activity }\end{array}$} & \multicolumn{2}{|c|}{$\begin{array}{l}\text { at least once a } \\
\text { week (regularly) }\end{array}$} & \multicolumn{2}{|c|}{$\begin{array}{l}\text { at least several } \\
\text { times a month } \\
\text { (occasionally) }\end{array}$} & \multicolumn{2}{|c|}{$\begin{array}{l}\text { once a month or } \\
\text { more seldom }\end{array}$} & \multicolumn{2}{|l|}{ never } & \multirow[t]{2}{*}{$\mathrm{X}^{2}$} & \multicolumn{2}{|c|}{$\begin{array}{l}95 \% \text { confidence interval } \\
\text { (regularly } \\
\text { occasionally) }\end{array}$} \\
\hline & $\begin{array}{l}\text { group } \\
1\end{array}$ & $\begin{array}{l}\text { group } \\
2\end{array}$ & $\begin{array}{l}\text { group } \\
1\end{array}$ & $\begin{array}{l}\text { group } \\
2\end{array}$ & $\begin{array}{l}\text { group } \\
1\end{array}$ & $\begin{array}{l}\text { group } \\
2\end{array}$ & $\begin{array}{l}\text { group } \\
1\end{array}$ & $\begin{array}{l}\text { group } \\
\end{array}$ & & group 1 & group 2 \\
\hline $\begin{array}{l}\text { nordic } \\
\text { walking }\end{array}$ & $8 \%$ & $2 \%$ & $16 \%$ & $6 \%$ & $12 \%$ & $10 \%$ & $64 \%$ & $83 \%$ & 16,155 & {$[20 \% ; 28 \%]$} & {$[6 \% ; 10 \%]$} \\
\hline hiking & $1 \%$ & $12 \%$ & $16 \%$ & $44 \%$ & $41 \%$ & $34 \%$ & $41 \%$ & $10 \%$ & 59,821 & {$[14 \% ; 20 \%]$} & {$[52 \% ; 60 \%]$} \\
\hline $\begin{array}{l}\text { skiing/ } \\
\text { snowboarding }\end{array}$ & $1 \%$ & $23 \%$ & $13 \%$ & $30 \%$ & $41 \%$ & $26 \%$ & $45 \%$ & $21 \%$ & 10,492 & {$[11 \% ; 17 \%]$} & [49\%;57\%] \\
\hline inline skating & $8 \%$ & $3 \%$ & $17 \%$ & $8 \%$ & $17 \%$ & $19 \%$ & $59 \%$ & $69 \%$ & 8,024 & {$[21 \% ; 29 \%]$} & {$[8 \% ; 14 \%]$} \\
\hline
\end{tabular}

\section{Motives}

Respondents from Burgenland and Tyrol rated the importance of green spaces for being physically active as high or very high. When analysing the data, the authors identified three major characteristics green spaces should feature in order to make them suitable for physical activities: closeness (group 1: 77\% "very important" or "important" +/-4\%; group 2: 73\% "very important" or "important" +/-4\%), cleanliness (group 1: $77 \%$ "very important" or "important" +/-4\%; group 2: 83\% "very important" or "important" +/-4\%) and naturalness (group 1: $76 \%$ "very important" or "important" +/-4\%; group 2: $85 \%$ "very important" or "important" $+/-3 \%$ ). These results show that, although the three most important conditions are the same in both groups, the ranking is different.

The main motives for doing sports and exercising in nature were nearly identical for both groups. These factors were health (group 1: 64\% "agree completely"; group 2: 65\% "agree completely") and fresh air (group 1: 60\% "agree completely"; group 2: 69\% "agree completely"). Beyond these general similarities, the 
significance of differences in motives was tested using the chi-squared test. The analyses revealed statistically significant differences in the following motives: Weight loss was more important for respondents living in Burgenland than those living in Tyrol $(X 2=6.398, P<0.05)$. In contrast, experiencing nature $(X 2=13.272, P<0.05)$ and being with friends $(X 2=13.110, P<0.05)$ are more relevant motives in Tyrol than in Burgenland.

\section{Barriers}

Most respondents (from both provinces) rated the outdoor sport facilities in their neighbourhood as very good. In fact, $93 \%(+/-2 \%)$ of the Burgenlanders and $99 \%(+/-1 \%)$ of the Tyroleans agreed or even completely agreed with the statement "There are many possibilities for being physically active in nature in my neighbourhood". In contrast, many respondents, and especially those living in Burgenland, disagreed with the statements "Sport clubs in neighbourhood offer many possibilities for being physically active in nature" (group 1: 49\% "disagree" +/- 4\%; group 2: 33\% "disagree" +/-4\%) and "My community does enough to ensure that citizens are being active in nature" (group 1: $58 \%$ "disagree" $+/-4 \%$; group 2: $35 \%$ "disagree" $+/-4 \%)$. This indicates that there is a need for action concerning organized outdoor sport activities.

Most barriers for doing outdoor sports refer to general obstacles for being physically active, such as lack of time (Burgenland: 69\%, Tyrol: 61\%). Barriers concerning the condition and design of green spaces seem to play only a minor role: Only $21 \%$ of respondents from Burgenland (+/-3\%) and $20 \%$ of respondents from Tyrol $(+/-3 \%)$ said that there should be more green spaces that enable physical activities in their neighbourhood. Only $8 \%$ of Burgenlanders $(+/-2 \%)$ and $5 \%$ of Tyroleans $(+/-2 \%)$ said that green spaces in their neighbourhoods were not attractive or even dirty. Although most respondents of both groups are generally satisfied with the design of green spaces in their neighbourhoods, special needs of the population were identified (see table 2).

Table 2. Desires of the population concerning designing green spaces in order to facilitate physically activity: group 1: $n=106:$ group 2: $n=128$

\begin{tabular}{lll}
\hline $\begin{array}{l}\text { Desires of the population concerning } \\
\text { designing green spaces in order to facilitate }\end{array}$ & $\begin{array}{l}\text { group } \\
\text { physically activity }\end{array}$ & $\begin{array}{l}\text { group } \\
\text { ph }\end{array}$ \\
\hline $\begin{array}{l}\text { more naturalness, being away from traffic } \\
\text { cleanliness }\end{array}$ & $13 \%$ & $19 \%$ \\
$\begin{array}{l}\text { better guiding system (marks, labeling) } \\
\text { more special infrastructure for young adults }\end{array}$ & $8 \%$ & $10 \%$ \\
$\begin{array}{l}\text { (skating hills, downhill trails, mountain bike } \\
\text { routes) }\end{array}$ & $8 \%$ & $13 \%$ \\
$\begin{array}{l}\text { larger areas and free zones } \\
\text { better accessibility }\end{array}$ & $3 \%$ & $9 \%$ \\
$\begin{array}{l}\text { more experience elements (e.g. experience } \\
\text { hills etc.) }\end{array}$ & $7 \%$ & $4 \%$ \\
$\begin{array}{l}\text { more organized sport events (e.g jogging } \\
\text { group) }\end{array}$ & $3 \%$ & $3 \%$ \\
\hline
\end{tabular}




\section{Expert recommendations}

Based on the results of the quantitative online survey, status quo and requirements analyses, as well as a SWOT (strenghts-weaknesses-opportunities-threats) analysis, experts working in the field of physical activity promotion created a catalogue of recommended actions concerning the design of green spaces to promote physical activity. The recommendations refer to the target group "Tyroleans and Burgenlanders between the ages of 18 and 35".

In general, the experts agreed that the results of the online survey show that respondents are very satisfied with both the quantity and quality of green spaces and outdoor sport facilities. However, there is room for improvement in the following areas:

- The guiding system, especially in Burgenland, should be more user-friendly.

- Experience elements should be developed (e.g. experience trails) based on the needs of different target groups (young parents, adolescents).

- Sport facilities for the most popular outdoor activities (e.g. jogging, biking) should be extended.

- Local populations should have easier access (low costs, good transport connections) to outdoor sport facilities.

- A network between different important stakeholders (e.g. sport clubs, communities, tourism organizations, conservation organizations) should be established to ensure the consistent communication and improvement of green spaces in terms of physical activity promotion.

- Green spaces and outdoor sport facilities should be maintained regularly.

- There should be more organized sporting events to ensure the sustainable utilization of outdoor sport facilities.

\section{DISCUSSION}

This study confirms the results of other Austrian studies concerning levels of physical activity and preferred sport activities in different provinces (Klimont et al., 2007; Weiß \& Russo, 2005; Zellmann \& Mayrhofer, 2010). In particular, the findings demonstrate that people living in Tyrol are generally more physically active and have different preferences concerning kinds of sport activities than those living in Burgenland. In addition, the results of the analysis highlighted a number of differences in outdoor physical activity behaviour between 18-35-year-old Tyroleans and Burgenlanders:

- The duration of exercise sessions in nature is significantly longer in Tyrol than in Burgenland.

- Respondents from Tyrol engage significantly more often in mountain sports (e.g. skiing, snowboarding, hiking) than those from Burgenland.

- Respondents from Burgenland go nordic walking and inline skating significantly more often than those from Tyrol.

- The amount of respondents who participate in sport clubs (e.g. hiking clubs) is higher in Tyrol than in Burgenland.

- Burgenlanders between the ages of 18 and 35 have different motives for doing outdoor sports than Tyroleans in the same age group.

The findings appear to support the assumption among Austrian experts working in the field of physical activity promotion that topographic conditions influence the physical activity behaviour of local populations. Despite the results of the present study, differences in topographic conditions are not likely to be the only reason for east-west differences. In a focus group, experts working in the field of physical activity promotion 
discussed other potential explanations, such as differences between Burgenland and Tyrol in modes of transportation in everyday life, attitudes towards sports, and political structures in health promotion.

In addition to alternative explanations for the study results, the study's limitations need to be taken into account when considering the findings. One of these limitations concerns the survey instrument. To date, no valid questionnaire for measuring physical activity behaviour has been developed.

One further limitation refers to the procedure of the online enquiry. The internet (virtual networks of universities, Facebook) was the only access to the study population. This means that people who are not members of one of these networks were unable to participate in the online survey. In addition, distributing the online survey via virtual networks of universities had the effect that mainly people with a high educational background (general qualification for university entrance or even bachelor's degree) responded to the survey. The mainly positive results of the present study may therefore be attributed to the fact that people with a higher educational background are more physically active and do more sports than those with a lower one (Weiß \& Russo, 2005).

Another shortcoming of the study is the method of disproportional sampling, which means that the results are not representative for all people between the ages of 18 and 35 living in Burgenland or Tyrol. In that context, the authors must also mention that the hypothesis that different topographic conditions are a reason for the east-west divide concerning physical activity in Austria was only partially tested. Two provinces, Burgenland and Tyrol, were chosen to represent the western and eastern regions of Austria. Other provinces were not considered. In addition, only people between the ages of 18 and 35 were included in the study. Overall, this target group includes different groups of people (e.g. adolescents, young parents). The population of the present study was overrepresented by young adults ages 18-25. The recommendations developed within the study therefore mainly address that population group.

\section{CONCLUSION}

Based on the data from this study, the authors conclude that the natural environment influences levels of physical activity as well as choice of sports activities among local populations. In addition, the results of the study appear to suggest that different topographic conditions are one plausible reason for the differences in levels of physical activity between people living in western regions of Austria and those living in eastern regions. However, since differences in topographic conditions are not likely to be the only reason, future studies are necessary to test other possible explanations for the east-west divide concerning physical activity behaviour in Austria. The present study has already generated some hypotheses.

However, the authors believe strongly that the development and design of green spaces, especially of nonstandardized, officially accessible outdoor facilities, will play a vital role in the future, mainly due to such factors as the increased importance of informal sports, the decreased utilization of traditional sport facilities, and the growing importance of sport motives (e.g. fun, health, experiencing nature), as well as the ongoing concentration of the population in urban areas. Based on the current findings, the authors recommend considering the desires of the population concerning the design of green spaces and the implementation of expert recommendations. The limitations of this study concerning the restricted study population can only be overcome by investigating the needs of other population groups (e.g. other age groups, people from other provinces) within future studies. One next step would be to explore the opinions of other professionals (e.g. city planners, conservationists) and to initiate cooperative actions to promote outdoor physical activity. This could be supported by multidisciplinary research actions. Once expert recommendations have been 
implemented, it would also be interesting to re-examine the physical activity behaviour of the population in order to explore the effect of (re)designing green spaces on this public health relevant factor.

\section{REFERENCES}

1. Brownson, R.C., Baker, E.A., Housemann, R.A., Brennan, L.K. \& Bacak, S.J. (2001). Environmental and Policy Determinants of Physical Activity in the United States. Am J Public Health, 91(12), pp.1995-2003.

2. Buber, R. \& Holzmüller, H. (Eds.). (2009). Qualitative Marktforschung: Konzepte - Methoden Analysen. Wiesbaden: Gabler.

3. Bundesamt für Naturschutz (Ed.). (2010). Naturschutz \& Gesundheit: Allianzen für mehr Lebensqualität. Bonn: Bundesamt für Naturschutz.

4. Cohen, D.A., Ashwood, J.S., Scott, M.M., Overton, A., Evenson, K.R., Staten, L.K., Porter, D., McKenzie, T.L. \& Catellier, D. (2006). Public Parks and Physical Activity Among Adolescent Girls. Pediatrics, 118(5), pp.1381-1389.

5. Coombes, E., Jones, A.P. \& Hillsdon, M. (2010). The relationship of physical activity and overweight to objectively measured green space accessibility and use. Soc Scie Med, 70(6), pp.816-822.

6. Cunningham, G. \& Michael, Y.L. (2004). Concepts guiding the study of the impact of the built environment on physical activity for older adults: a review of the literature. Am J Health Promot, 18(6), pp.435-443.

7. Dahlgren, G. \& Whitehead, M. (1991). Policies and strategies to promote social equity in health. Stockholm: Institute for Future Studies.

8. De Vries, S. (2010). Vitamin G: Urban green planning for human health and well-being. In Bundesamt für Naturschutz (Ed.), Naturschutz \& Gesundheit: Allianzen für mehr Lebensqualität (pp. 32-34). Bonn: Bundesamt für Naturschutz.

9. Ellaway, A., Macintyre, S. \& Bonnefoy, X. (2005). Graffiti, greenery, and obesity in adults: secondary analysis of European cross section survey. Brit Med J, 331(7517), pp.611-612.

10. Fuchs, R. (2003). Sport, Gesundheit und Public Health. Göttingen: Hogrefe.

11. Hartig, T. (2008). Environment matters: Where people walk can affect the health benefits that they realize. In Tourismus Zentrale Saarland (Ed.), Gesundheitskongress Wandern: "Regeneration durch Natur" (pp. 117-144). Saarbrücken: Tourismus Zentrale Saarland.

12. Hillsdon, M., Panter, J., Foster, C. \& Jones, A. (2006). The relationship between access and quality of urban green space with population physical activity. Public Health, 120(2), pp.1127-1132.

13. Humpel, N., Owen, N. \& Leslie, E. (2002). Environmental factors associated with adults' participation in physical activity. Am J Prev Med, 22(3), pp.188-199.

14. Kaczynski, A.T. \& Henderson, K.A. (2008). Parks and recreation settings and active living: a review of associations with physical activity function and intensity. J Phys Act Health, 5(4), pp.619-632.

15. Klimont, J., Kytir, J. \& Leitner, B. (2007). Österreichische Gesundheitsbefragung 2006/07: Hauptergebnisse und Methodische Dokumentation. Wien: Bundesministerium für Gesundheit.

16. Mayerhofer, W. (2009). Das Fokusgruppeninterview. In R. Buber \& H. Holzmüller (Eds.). Qualitative Marktforschung: Konzepte - Methoden - Analysen (pp. 479-488). Wiesbaden: Gabler.

17. Schwarz, L. (2002). Kleinräumige Modellierung von Naturräumen für Österreich ausgehend von edaphischen und klimatischen Faktoren in digitaler Form (Diploma thesis). Wien: Fakultät für Human- und Sozialwissenschaften der Universität Wien. 
18. Sprecher, H. (2010). Bewegung und Motivation in der zweiten Lebenshälfte: Gründe für und gegen sportliche Aktivität: Vergleiche zwischen Sportlern und Nichtsportlern. Saarbrücken: VDM Verlag Dr. Müller.

19. Statistik Austria. (2012). Bevölkerungsstand 1.1.2012. Wien: Statistik Austria.

20. Titze, S., Ring-Dimitriou, S., Schober, P.H., Halbwachs, C., Samitz, G., Miko, H.C., Lercher, P., Stein, K.V., Gäbler, C., Bauer, R., Gollner, E., Windhaber, J., Bachl, N., Dorner, T.E. \& Arbeitsgruppe Körperliche Aktivitä/Bewegung/Sport der Österreichischen Gesellschaft für Public Health. (2010). Austrian Recommendations for Health-Enhancing Physical Activity. Wien: Bundesministerium für Gesundheit.

21. Toftager, M., Ekholm, O., Schipperijn, J., Stigsdotter, U., Bentsen, P., Gronbäck, M., Randrup, T.B. \& Kamper-Jorgensen, F. (2011). Distance to green space and physical activity: a Danish national representative survey. J Phys Act Health, 8(6), pp.741-749.

22. Tourismus Zentrale Saarland (Ed.). (2008). Gesundheitskongress Wandern: "Regeneration durch Natur". Saarbrücken: Tourismus Zentrale Saarland.

23. Urbas, E., Leitner, B., Hackl, M., Klimont, J. \& Vutuc, C. (2008). Atlas of Mortality in Austria by Causes of Death 1998/2004. Wien: Statistik Austria.

24. Weiß, O. \& Russo, M. (2005). Mehr Österreicherlinnen zum Sport: Eine Aktivierungsstudie zur Förderung des Sportengagements in Österreich. Wien: Österreichische Bundes-Sportorganisation BSO \& Bundesministerium für Bildung, Wissenschaft und Kultur.

25. Witten, K., Hiscock, R., Pearce, J. \& Blakely, T. (2008). Neighbourhood access to open spaces and the physical activity of residents: a national study. Prev Med, 47(3), pp.299-303.

26. World Health Organization. (1986). Ottawa Charter of Health Promotion. Ottawa: World Health Organization.

27. World Health Organization. (2010). Global Recommendations on physical activity for health. Geneva: World Health Organization.

28. Zellmann, P. \& Mayrhofer, S. (2010). So sportlich ist Österreich: Die Sportausübung im Europaund Bundesländer-Vergleich. Retrieved January 5, 2014, from http://www.freizeitforschung.at/data/forschungsarchiv/2010/89.\%20FT\%20122010_So\%20sportlich\%20ist\%200esterreich.pdf 